\title{
Chronic Neuropathic Pain: It's about the Rhythm
}

\author{
Zeynab Alshelh, ${ }^{1}$ Flavia Di Pietro, ${ }^{1}$ Andrew M. Youssef, ${ }^{1}$ Jenna M. Reeves, ${ }^{1}$ Paul M. Macey, ${ }^{3}$ E. Russell Vickers, ${ }^{1}$ \\ Christopher C. Peck, ${ }^{2}$ Greg M. Murray, ${ }^{2}$ and ${ }^{-L u k e ~ A . ~ H e n d e r s o n ~}{ }^{1}$ \\ ${ }^{1}$ Department of Anatomy and Histology and ${ }^{2}$ Faculty of Dentistry, University of Sydney, Sydney, New South Wales 2006, Australia, and ${ }^{3}$ School of Nursing \\ and Brain Research Institute, University of California, Los Angeles, Los Angeles, California 90095
}

The neural mechanisms underlying the development and maintenance of chronic neuropathic pain remain unclear. Evidence from human investigations suggests that neuropathic pain is associated with altered thalamic burst firing and thalamocortical dysrhythmia. Additionally, experimental animal investigations show that neuropathic pain is associated with altered infra-slow $(<0.1 \mathrm{~Hz})$ frequency oscillations within the dorsal horn and somatosensory thalamus. The aim of this investigation was to determine whether, in humans, neuropathic pain was also associated with altered infra-slow oscillations within the ascending "pain" pathway. Using resting-state functional magnetic resonance imaging, we found that individuals with orofacial neuropathic pain have increased infra-slow oscillatory activity throughout the ascending pain pathway, including within the spinal trigeminal nucleus, somatosensory thalamus, thalamic reticular nucleus, and primary somatosensory cortex. Furthermore, these infra-slow oscillations were temporally coupled across these multiple sites and occurred at frequencies similar to calcium waves in activated astrocytes. The region encompassing the spinal trigeminal nucleus also displayed increased regional homogeneity, consistent with a local spread of neural activity by astrocyte activation. In contrast, no increase in oscillatory behavior within the ascending pain pathway occurred during acute noxious stimuli in healthy individuals. These data reveal increased oscillatory activity within the ascending pain pathway that likely underpins increased thalamocortical oscillatory activity, a self-sustaining thalamocortical dysrhythmia, and the constant perception of pain.

Key words: astrocytes; infra-slow oscillations; orofacial pain; regional homogeneity; spinal trigeminal nucleus; thalamocortical rhythm

Significance Statement

Chronic neuropathic pain is associated with altered thalamic firing and thalamocortical dysrhythmia. The mechanisms responsible for these changes remain unknown. In this study, we report in individuals with neuropathic pain increased oscillatory neural activity within the ascending pain pathway with evidence that these changes result from altered neural-astrocyte coupling. We propose a series of neural and glial events after nerve injury that result in the generation of altered thalamocortical activity and a persistent neuropathic pain state. Defining the underlying mechanisms responsible for neuropathic pain is critical if we are to develop more effective treatment regimens.

\section{Introduction}

Neuropathic pain (NP) is a disease state with an enormous socioeconomic burden and with unmet needs for the population. In the United States alone, it is estimated to afflict $\sim 10 \%$ of the population, costing on average $\$ 17,000$ per patient yearly (Wang et al., 2009a,c). Additionally, there are frequent

Received July 21, 2015; revised Nov. 27, 2015; accepted Dec. 14, 2015.

Author contributions: F.D.P., J.M.R., P.M.M., E.R.V., C.C.P., G.M.M., and L.A.H. designed research; Z.A., F.D.P., A.M.Y., J.M.R., C.C.P., G.M.M., and L.A.H. performed research; Z.A., A.M.Y., and P.M.M. analyzed data; Z.A., F.D.P., E.R.V., and L.A.H. wrote the paper.

We are grateful to Dr. Gustin for help with data collection. This work was supported by funding from the Australian National Health and Medical Research Council and the N.W.G. Macintosh Memorial Fund.

The authors declare no competing financial interests.

Correspondence should be addressed to Luke A. Henderson, Department of Anatomy and Histology, F13, University of Sydney, Sydney, New South Wales 2006, Australia. E-mail: Iukeh@anatomy.usyd.edu.au.

DOI:10.1523/JNEUROSCI.2768-15.2016

Copyright $\odot 2016$ the authors $\quad 0270-6474 / 16 / 361008-11 \$ 15.00 / 0$ clinical misdiagnoses as a result of the lack of quantitative and validated tests, and current treatment regimens are ineffective in a significant number of individuals. Hindering our ability to improve diagnoses and treatment is our poor understanding of the neural mechanisms responsible for the development and maintenance of chronic NP. Surprisingly, although acute noxious stimuli evoke robust signal increases in a welldescribed set of neural structures (Farrell et al., 2005) and individuals with chronic pain display increased activation during acute noxious stimuli in these same regions (Gracely et al., 2002; Giesecke et al., 2004), multiple human brain imaging investigations have not found robust increases in ongoing blood flow in these same regions in individuals with chronic pain, particularly NP. Indeed, the most consistent difference is a thalamic blood flow decrease (Hsieh et al., 1995; Iadarola et al., 1995; Moisset and Bouhassira, 2007; Youssef et al., 2014). 
Despite the apparent lack of ongoing blood flow increases in most of the ascending pain pathway, NP is associated with altered thalamic firing, including increased burst firing in the somatosensory thalamus without an overall increase in activity (Lenz et al., 1989). Experimental animal investigations confirm that increased somatosensory thalamus burst firing is associated with NP and furthermore have revealed that this altered firing occurs in a rhythmic manner, with burst intensity oscillating at infraslow frequencies (Gerke et al., 2003; Iwata et al., 2011). It is thought that this altered thalamic firing underpins the thalamocortical dysrhythmia that occurs in individuals with NP and that results in the constant perception of pain (Sarnthein et al., 2006; Walton and Llinás, 2010). Coincidently, thalamic astrocytes display calcium wave oscillations that modulate neurotransmitter release from adjacent neurons, at approximately the same infraslow frequency range as the thalamic neuronal oscillations reported in animal models of NP (Crunelli et al., 2002), and it has been shown that NP is associated with astrocyte activation within the ascending pain pathway (Okada-Ogawa et al., 2009; Shi et al., 2012; Ji et al., 2013). Thus, it is conceivable that, in individuals with NP, an increase in oscillatory astrocyte activity within the dorsal horn and/or somatosensory thalamus results in an increase thalamocortical oscillatory activity, a self-sustaining thalamocortical dysrhythmia, and the constant perception of pain.

We investigated whether individuals with NP displayed increased infra-slow oscillatory activity in ascending pain pathways, including the level of the primary afferent synapse and whether this activity dominates information flow throughout the brain. Because we propose that pathological processes including chronic astrocyte activation play a critical role in generating infra-slow oscillations, we hypothesized that, in healthy individuals, activation of the ascending pain pathway by an acute noxious stimulus does not increase infra-slow oscillatory activity.

\section{Materials and Methods}

Subjects. Seventeen subjects with chronic orofacial NP (14 females; mean \pm SEM age, $50.6 \pm 2.8$ years) and 44 pain-free controls ( 33 females; mean age, $45.9 \pm 2.0$ years) were recruited for the study. There was no significant difference in age ( $t$ test, $p>0.05)$ or gender composition $\left(\chi^{2}\right.$ test, $p>0.05$ ) between the two subject groups. NP subjects were diagnosed using the Liverpool criteria as having posttraumatic neuropathy (Nurmikko and Eldridge, 2001).

During the $7 \mathrm{~d}$ before the MRI session, each subject kept a pain diary recording the intensity of their ongoing pain, three times a day. Subjects rated the intensity of their pain using a $10 \mathrm{~cm}$ horizontal visual analog scale (VAS), with 0 indicating "no pain" and 10 indicating "the most intense imaginable pain." These pain intensity scores were then averaged over the $7 \mathrm{~d}$ period to create a mean pain intensity score. On the day of the MRI scanning, each NP subject outlined the location of their ongoing pain on a standard drawing of the head and completed a McGill Pain Questionnaire, the Beck's Depression Inventory (BDI; Beck et al., 1961), and the Pain Catastrophizing Scale (PCS; Sullivan et al., 1995). Table 1 shows NP subject characteristics, including pain duration, pain location, $7 \mathrm{~d}$ pain intensity, medication, depression, and pain catastrophizing scores. Informed written consent was obtained for all procedures according to the Declaration of Helsinki, and the study was approved by our local Institutional Human Research Ethics Committees. Data from 13 of the $17 \mathrm{NP}$ subjects were used in previous investigations (Gustin et al., 2011; Henderson et al., 2013; Wilcox et al., 2015).

MRI acquisition. All NP and control subjects lay supine on the bed of a 3 tesla MRI scanner (Achieva; Philips) with their head immobilized in a tight-fitting head coil. With each subject relaxed and at rest, a series of 180 gradient echo echo-planar functional MRI (fMRI) image volumes using blood oxygen level-dependent contrast were collected. Each image volume contained 35 axial slices covering the entire brain (field of view,
Table 1. PTN subject characteristics

\begin{tabular}{|c|c|c|c|c|c|c|c|}
\hline Subjec & $\begin{array}{l}\text { Age } \\
\text { ject (years) }\end{array}$ & Gender & $\begin{array}{l}\text { Pain } \\
\text { duration } \\
\text { (years) }\end{array}$ & $\begin{array}{l}\text { Pain } \\
\text { intensity } \\
\text { (VAS) }\end{array}$ & Location & n Analgesic medication & BDI PC \\
\hline 1 & 51 & Male & 3.5 & 2.1 & Right & None & 610 \\
\hline 2 & 47 & Female & 5 & 1.1 & Left & None & $24 \quad 47$ \\
\hline 3 & 52 & Female & 1.5 & 6.9 & Bilateral & $\begin{array}{l}\text { Oxycodone hydrochloride, } \\
\text { paracetamol }\end{array}$ & 1829 \\
\hline 4 & 55 & Female & 2 & 5.2 & Left & $\begin{array}{l}\text { Docusate sodium; sennosides, } \\
\text { amitriptyline, gabapentin, } \\
\text { oxycodone, paracetamol }\end{array}$ & 2125 \\
\hline 5 & 42 & Female & 11 & 4.8 & Right & Carbamazepine & 3436 \\
\hline 6 & 54 & Female & 6.5 & 1.6 & Right & Amitriptyline & 920 \\
\hline 7 & 44 & Female & 2 & 6.4 & Left & None & 1115 \\
\hline 8 & 41 & Female & 3.5 & 4.0 & Left & None & 611 \\
\hline 9 & 67 & Female & 14 & 8.4 & Left & None & 429 \\
\hline 10 & 43 & Male & 16 & 5.8 & Left & Desvenlafaxine & 59 \\
\hline 11 & 44 & Female & 1.5 & 1.2 & Right & $\begin{array}{l}\text { Ibuprofen, codeine } \\
\text { phosphate, paracetamol }\end{array}$ & 1925 \\
\hline 12 & 65 & Female & 7 & 2.5 & Left & Amitriptyline, paracetamol & 611 \\
\hline 13 & 50 & Female & 7 & 0.5 & Right & None & 62 \\
\hline 14 & 67 & Female & 20 & 4.2 & Right & $\begin{array}{l}\text { Thyroxine sodium, rosuvastatin, } \\
\text { venlafaxine, pregabalin, } \\
\text { phenylethylamine, } \\
\text { ergotamine }\end{array}$ &, 3218 \\
\hline 15 & 67 & Female & 3 & 8.4 & Left & None & \\
\hline 16 & 43 & Male & 9 & 5.8 & Left & Desvenlafaxine & 3029 \\
\hline 17 & 44 & Female & 7.5 & 1.2 & Right & None & 535 \\
\hline
\end{tabular}

$240 \times 240 \mathrm{~mm}$; matrix size, $80 \times 78$; slice thickness, $4 \mathrm{~mm}$; repetition time, $2000 \mathrm{~ms}$; echo time, $30 \mathrm{~ms}$; flip angle, $90^{\circ}$ ). In each subject, a high-resolution 3D T1-weighted anatomical image set covering the entire brain was collected (turbo field echo; field of view, $250 \times 250 \mathrm{~mm}$; matrix size, $288 \times 288$; slice thickness, $0.87 \mathrm{~mm}$; repetition time, 5600 $\mathrm{ms}$; echo time, $2.5 \mathrm{~ms}$; flip angle, $8^{\circ}$ ).

In addition, in 15 of the control subjects, a catheter connected to a syringe filled with hypertonic saline (5\%) was placed into the right masseter muscle midway between its upper and lower borders. The catheter was connected to an infusion pump with a $10 \mathrm{ml}$ syringe placed outside the scanner room. An infusion of hypertonic saline $(4 \mathrm{ml} / \mathrm{h})$ into the right masseter muscle was then started, and the subject indicated by pushing a buzzer when the pain intensity reached a score of 5 of 10 on a numerical 11 point VAS. While in pain, a series of $180 \mathrm{fMRI}$ image volumes were then collected using the same parameters as described above. Each subject was instructed to push a buzzer once if the pain fell below 5 and twice if it increased above 5 , and the infusion rate was adjusted accordingly to maintain the pain intensity at 5 of 10 . After the scan, each subject was asked to rate the average pain during the scan on a $10 \mathrm{~cm}$ horizontal VAS. Each NP and control subject was scanned only once, and all data were used for additional analysis. Furthermore, to reduce the potential effects of software upgrades and other factors that can alter signal-to-noise ratios, we collected the control and NP subject data randomly throughout a 3.5 year period during which this investigation was conducted.

MRI analysis. Using SPM12 (Friston et al., 1995), all functional magnetic resonance images were motion corrected, and global signal drifts were removed using the detrending method described by Macey et al. (2004), spatially normalized to the Montreal Neurological Institute (MNI) template, and spatially smoothed (6 mm full-width half-maximum Gaussian filter). In no subject was there significant movement $(>0.5 \mathrm{~mm}$ in any direction). In those NP subjects with pain restricted to the left side of the face $(n=9)$, resting fMRI scans were reflected across the midline so that, in all NP subjects, the right side was ipsilateral to ongoing pain. Given this, the individual analyzing the data was not blinded to the subject groups. To assess thalamic oscillatory activity, we placed a cuboid over the left (contralateral) thalamus, covering 18, 24, and $15 \mathrm{~mm}$ in the $x, y$, and $z$ directions, respectively. This cube was then divided into 240 individual volumes of interest (VOIs) that were $3 \times 3 \times$ 

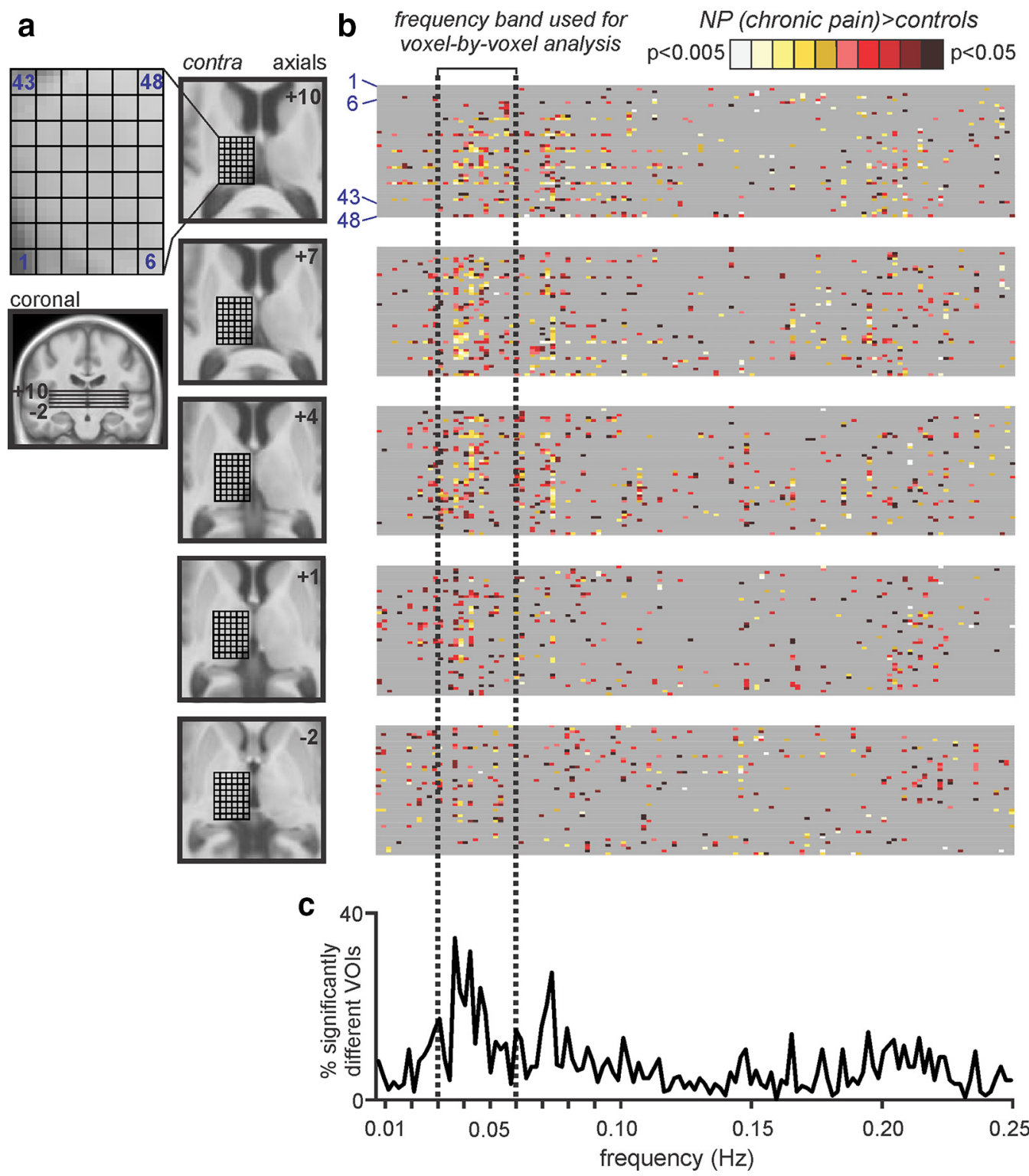

Figure 1. Infra-slow oscillations within the thalamus. $\boldsymbol{a}$, A cuboid $18 \times 24 \times 15 \mathrm{~mm}$ consisting of 240 individual V0ls was placed over the left (contralateral to highest pain) thalamus in 44 controls and 16 subjects with orofacial NP. Slice locations are indicated by the horizontal lines on the coronal section and the numbers to the top right of each axial slice in MNI space. At each rostrocaudal level of the thalamus, $48 \mathrm{VOIs}$ were assessed for significant power differences. $\boldsymbol{b}$, Each gray band beside an axial image consists of a row for each V0I in that slice, with spectral power differences between control and NP subjects (controls $>$ NP or controls $<N P$ ) at frequencies between 0.006 and $0.25 \mathrm{~Hz}$ color coded for significance ( $p$ value). Gray represents no significant difference. $c$, A plot of the percentage of significantly different voxels over the entire frequency spectrum revealed that the frequency band $0.03-0.06 \mathrm{~Hz}$ had the highest percentage of significantly different VOls. This frequency band was used for all subsequent analysis.

$3 \mathrm{~mm}$ each (Fig. 1a). The individual resting fMRI signal intensity changes in each of these 240 VOIs were then derived for each of the 44 control and 17 NP subjects from the nonspatially smoothed fMRI image sets. Power spectra based on fast Fourier transforms were calculated using MATLAB software (MathWorks) for each individual subject's resting fMRI signal. Power values were then averaged over each VOI for the control and NP groups, and significant differences between power spectra were determined at $0.002 \mathrm{~Hz}$ intervals from 0.006 to $0.25 \mathrm{~Hz}$ (two-sample $t$ tests, $p<0.05)$. Significant differences between control and NP groups were color coded for significance, and the percentage of significantly different VOIs at each frequency were plotted. This analysis revealed that the frequency band with the greatest number of significantly different VOIs was $0.03-0.06 \mathrm{~Hz}$, and this band was used for subsequent analyses.

Low-frequency amplitude analysis. Using the SPM toolbox REST (Song et al., 2011), we calculated the sum of amplitudes of low-frequency fluctuations (ALFFs) between 0.03 and $0.06 \mathrm{~Hz}$ for each voxel in control and NP subjects using the spatially smoothed fMRI image sets. In addition, we divided these ALFF values by total power over the entire frequency range to obtain fractional ALFF (fALFF) values for each voxel. Both ALFFs and fALFFs have been shown to have high test-retest reliability, particularly in gray matter, and reliability is reportedly greater in ALFFs than fALFFs (Zuo et al., 2010). Furthermore, parcellation-based reliability analyses demonstrate highly consistent and reliable rank ordering of infra-slow oscillatory power across the brain. These findings are consistent with ALFFs and fALFFs reflecting neuronal activity. Significant differences between groups were then determined using a two-sample random-effects procedure with age and gender as nuisance variables for both ALFF and fALFF values $(p<0.05$, false discovery rate corrected, minimum cluster size of 10 voxels). For each significant cluster, power spectra were calculated from resting percentage change fMRI signals, and the power at each frequency was calculated. We then plotted the mean power between 0.03 and $0.06 \mathrm{~Hz}$ for control and NP subjects.

To determine the potential effects of head movement, for each movement parameter $(x, y, z$, pitch, roll, yaw), power spectra were calculated, 

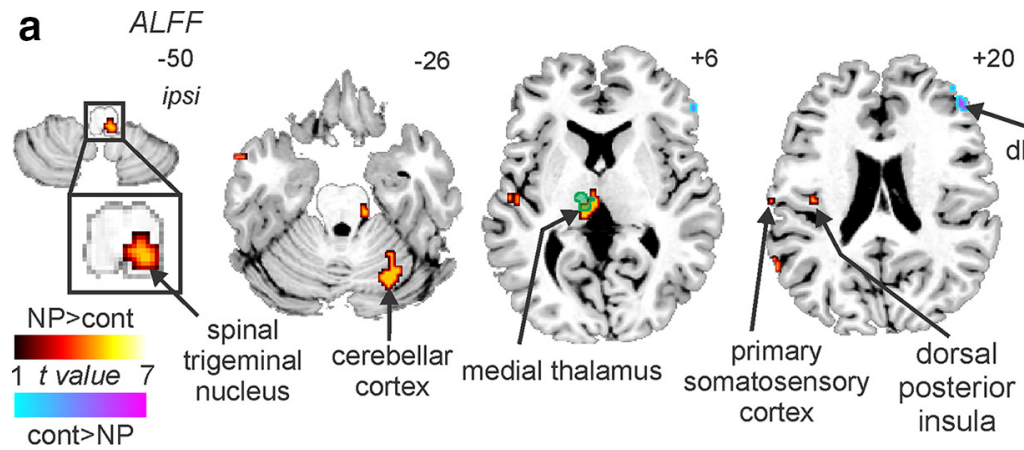

b $\quad$ FALFF
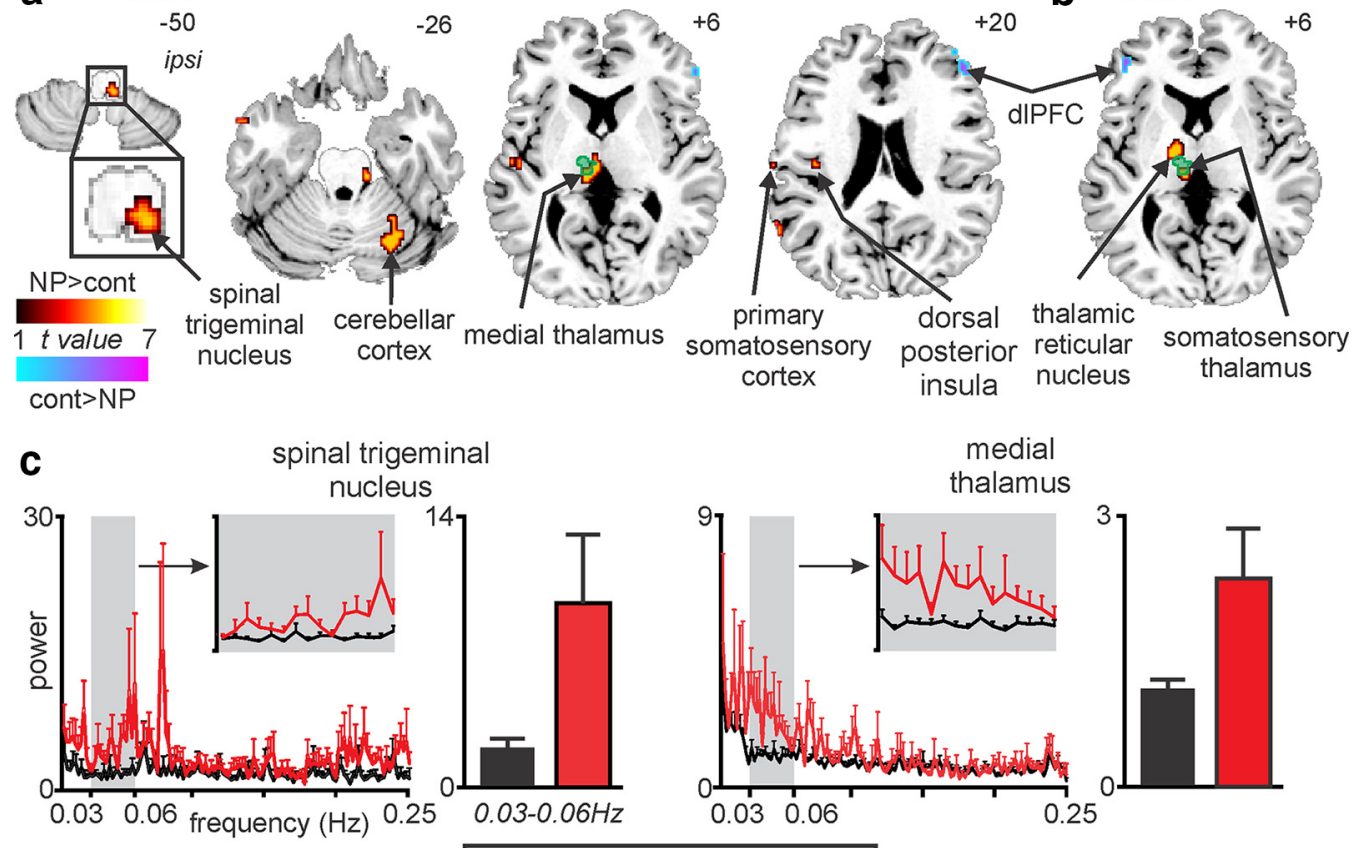

thalamus
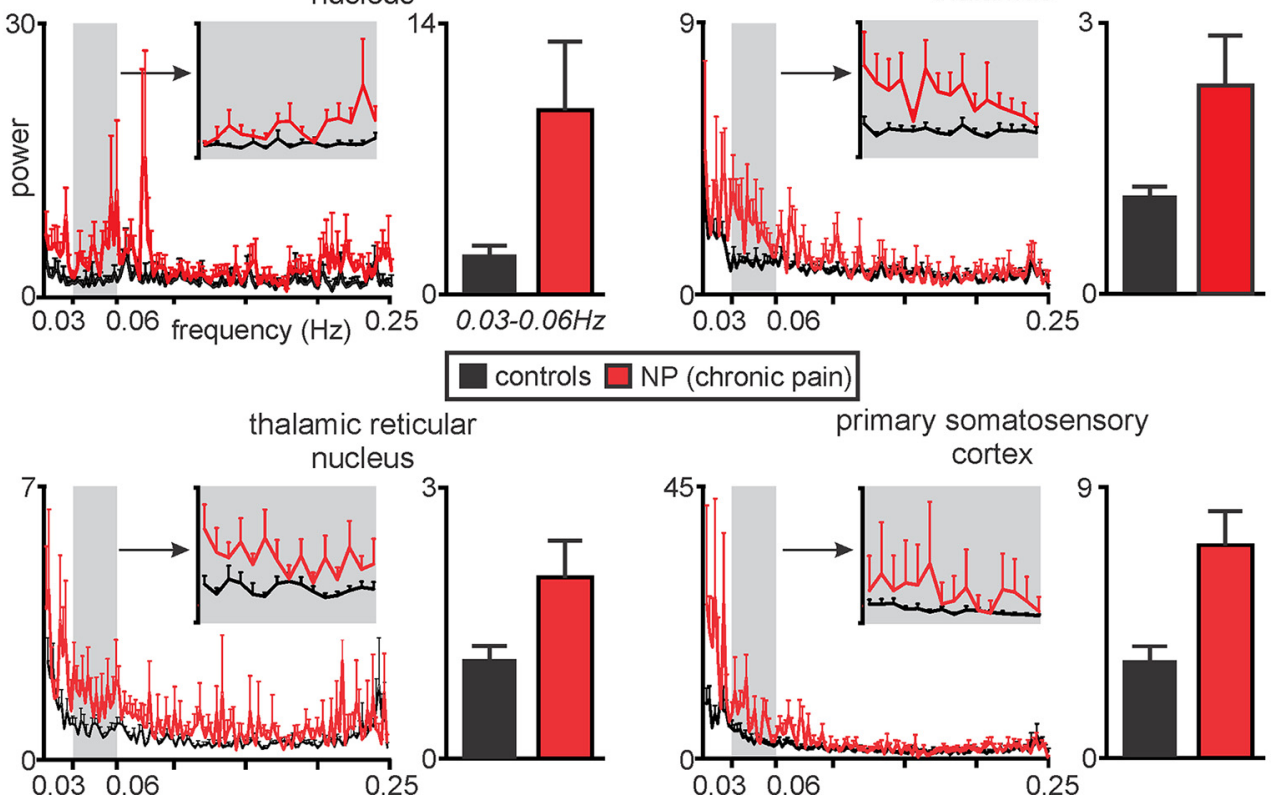

Figure 2. NP is associated with increased infra-slow oscillation power in the ascending pain pathway. Brain regions in which NP subjects had significantly increased (hot color) or decreased (cool color) ALFFs ( $\boldsymbol{a}$ ) and fALFFs ( $\boldsymbol{b}$; random effects, $p<0.05$, false discovery rate corrected, minimum cluster size of 10 voxels). Location of each axial slice in MNI space is indicated at the top right. The green shading indicates the thalamic region activated during innocuous brushing of the right lip, i.e., the orofacial somatosensory thalamus. NP is associated with increased infra-slow oscillations in the region of the primary afferent synapse (spinal trigeminal nucleus), as well as other parts of the ascending pain pathway. dlPFC, Dorsolateral prefrontal cortex. $c$, Power spectrum plots of four clusters in which power in the $0.03-0.06 \mathrm{~Hz}$ range was significantly increased in NP subjects (red) compared with controls (black). Plots of the mean \pm SEM power between 0.03 and $0.06 \mathrm{~Hz}$ are shown for controls and NP subjects. Note that, at frequencies above $0.06 \mathrm{~Hz}$, power was remarkably similar in both control and NP subjects. cont, Controls; ipsi, ipsilateral.

and the mean power between 0.03 and $0.06 \mathrm{~Hz}$ in control and NP groups were compared ( $p<0.05$, two-tailed, two-sample $t$ test). The effects of BDI and PCS were determined by assessing their relationships with $0.03-$ $0.06 \mathrm{~Hz}$ power in significant clusters in NP subjects $(p<0.05)$. The effect of medication on infra-slow oscillations was determined by comparing $0.03-0.06 \mathrm{~Hz}$ power in each significant cluster in NP subjects taking analgesic medications $(n=9)$ with those not taking medication $(n=8$; $p<0.05$, two-tailed, two-sample $t$ test). In addition, the effects of laterality were tested by reflecting each significant cluster across the midline and comparing mean power between $0.03-0.06 \mathrm{~Hz}$ in control and NP groups ( $p<0.05$, two-tailed, two-sample $t$ test). Finally, to determine whether changes in low-frequency oscillations were temporally coupled between the resulting significant clusters, cross-correlations were performed between resting fMRI signal intensity changes in each significant cluster in control and NP subjects (5 volume moving average applied to each cross-correlation curve).

Degree centrality analysis. To assess the influence of infra-slow frequency oscillations on local network connectivity, we measured degree centrality. Using the DPARSF toolbox (Chao-Gan and Yu-Feng, 2010), the preprocessed images were bandpass filtered $(0.03-0.06 \mathrm{~Hz})$, and voxel-based graphs were generated for each individual. Correlations between fMRI time series of each voxel with every other voxel in the brain were computed, resulting in a correlation matrix (minimum correlation $r$ value of 0.25). A binary, undirected adjacency matrix was then obtained, and degree centrality was calculated by counting the number of significant correlations between each voxel and all other voxels. For NP subjects, voxels with the greatest degree centrality were determined using a one-sample $t$ test $(p<0.05$, false discovery rate corrected, minimum cluster size of 10 voxels). To determine whether the resulting significant clusters differed between NP and control subjects, degree centrality values were extracted from each cluster in all subjects and compared using two-sample $t$ tests (two-tailed, two-sample $t$ test, $p<0.05$ ).

Local homogeneity analysis. To determine the role of factors such as the influence of astrocyte activation on neural function (albeit indirect evidence), we measured Kendall's coefficient of concordance (KCC), which evaluates the similarity of the time series within each voxel and its nearest neighbors. Using the DPARSF toolbox (Chao-Gan and Yu-Feng, 2010), the preprocessed images were bandpass filtered $(0.03-0.06 \mathrm{~Hz})$, and voxel-based graphs were generated for each individual subject. For each voxel, the KCC was computed from the time course of that voxel and its 19 neighboring voxels. Significant differences in regional homogeneity between NP and controls subjects were then determined using a twosample random-effects procedure $(p<0.05$, false discovery rate corrected, minimum cluster size of 10 voxels).

Acute pain analysis. Finally, we determined changes in infra-slow frequency oscillations $(0.03-0.06 \mathrm{~Hz})$ in 15 subjects during acute noxious 
Table 2. MNI coordinates, cluster size, and $t$ score for regions of significant difference between control and NP patients

\begin{tabular}{|c|c|c|c|c|c|}
\hline \multirow[b]{2}{*}{ Brain region } & \multicolumn{3}{|c|}{ MNI coordinate } & \multirow[b]{2}{*}{ Cluster size } & \multirow[b]{2}{*}{ tscore } \\
\hline & $x$ & $y$ & $z$ & & \\
\hline \multicolumn{6}{|l|}{ Amplitudes of low-frequency oscillations } \\
\hline Right dorsolateral prefrontal cortex & 8 & 30 & 20 & 50 & 4.41 \\
\hline \multicolumn{6}{|l|}{$\mathrm{NP}>$ controls } \\
\hline Ipsilateral spinal trigeminal nucleus & 6 & -40 & -50 & 31 & 4.33 \\
\hline Ipsilateral cerebellar cortex & 24 & -66 & -26 & 114 & 4.09 \\
\hline Contralateral somatosensory thalamus & -8 & -24 & 6 & 105 & 5.42 \\
\hline Contralateral dorsal posterior insula & -40 & -16 & 20 & 558 & 3.62 \\
\hline Contralateral S1 & -64 & -18 & 18 & 5 & 4.98 \\
\hline \multicolumn{6}{|c|}{$\begin{array}{l}\text { Fractional amplitudes of low-frequency oscillations } \\
\qquad N P>\text { controls }\end{array}$} \\
\hline Contralateral somatosensory thalamus & -6 & -24 & 8 & 31 & 4.84 \\
\hline Contralateral TRN & -12 & -10 & 6 & 28 & 4.40 \\
\hline \multicolumn{6}{|l|}{ Degree centrality } \\
\hline Ipsilateral spinal trigeminal nucleus & 10 & -38 & -48 & 26 & 13.89 \\
\hline Contralateral dorsolateral pons & -8 & -38 & -34 & 40 & 13.27 \\
\hline Ipsilateral cerebellar cortex & 24 & -70 & -30 & 199 & 17.57 \\
\hline Contralateral cerebellar cortex & -26 & -88 & -32 & 66 & 15.41 \\
\hline \multirow[t]{2}{*}{ Ipsilateral insula } & 40 & 8 & 0 & 40 & 16.42 \\
\hline & 40 & -4 & 10 & 17 & 12.81 \\
\hline Contralateral medial thalamus & -6 & -24 & 10 & 29 & 12.84 \\
\hline Contralateral TRN & -12 & -8 & 4 & 23 & 15.18 \\
\hline \multirow[t]{2}{*}{ Contralateral S1 } & -60 & -12 & 34 & 31 & 13.05 \\
\hline & -50 & -16 & 46 & 53 & 10.21 \\
\hline \multirow[t]{3}{*}{ Ipsilateral dorsolateral prefrontal cortex } & 38 & 38 & 8 & 25 & 17.25 \\
\hline & 38 & 2 & 34 & 61 & 15.10 \\
\hline & 28 & 22 & 48 & 16 & 13.14 \\
\hline Contralateral dorsolateral prefrontal cortex & -28 & -20 & 42 & 70 & 14.15 \\
\hline Mid-cingulate cortex & -2 & -12 & 28 & 33 & 13.19 \\
\hline \multicolumn{6}{|l|}{ Regional homogeneity } \\
\hline \multicolumn{6}{|l|}{$\mathrm{NP}>$ controls } \\
\hline Ipsilateral spinal trigeminal nucleus & 6 & -40 & -48 & 14 & 5.97 \\
\hline Ipsilateral cerebellar cortex & 20 & -52 & -18 & 21 & 5.03 \\
\hline \multirow[t]{3}{*}{ Contralateral cingulate cortex } & -4 & -32 & 28 & 64 & 6.36 \\
\hline & -6 & -4 & 46 & 76 & 6.19 \\
\hline & -8 & 20 & 34 & 36 & 5.80 \\
\hline
\end{tabular}

stimulus (masseter muscle pain) compared with all 44 controls. We calculated ALFF and fALFF maps using the spatially smoothed fMRI image sets, and significant differences between controls and acute pain were determined for both ALFF and fALFF values using a two-sample random-effects procedure with age and gender as nuisance variables $(p<0.05$, false discovery rate corrected, minimum cluster size of 10 voxels). Furthermore, for those clusters that displayed a significant increase in infra-slow frequency oscillations in NP subjects during the first analysis, signal intensity changes were extracted for each of the subjects during acute pain and in controls. For each cluster, power spectra were calculated, and significant differences between acute pain and no pain subjects were determined in the same process described above (two-sample $t$ test, $p<0.05)$. The anatomical locations of each significant cluster were confirmed using the Atlas of the Human Brainstem and Cerebellum (Duvernoy, 1995) and the Atlas of the Human Brain (Mai et al., 2007).

\section{Results}

\section{Altered infra-slow oscillations in ascending pain pathways}

Power spectra based on fast Fourier transforms of resting fMRI signal intensity fluctuations within the left thalamus (contralateral to highest ongoing pain) revealed that the greatest number of voxels in which power was significantly different in NP subjects compared with controls occurred within the frequency band $0.03-0.06 \mathrm{~Hz}$ (Fig. 1b). Using this restricted frequency range $(0.03-0.06 \mathrm{~Hz})$, a voxel-by-voxel analysis revealed a pattern of difference that closely overlapped the ascending pain pathway (Fig. 2a,b). That is, NP subjects had a significantly increased infra-slow oscillation power in the dorsolateral medulla in the region of the ipsilateral (right) spinal trigeminal nucleus subnucleus caudalis/interpolaris (SpV; mean \pm SEM, 0.03-0.06 Hz power; controls, $2.2 \pm 0.4$; NP, $9.5 \pm 3.6 ; p=0.0007$ ), contralateral medial thalamus encompassing the mediodorsal, centrolateral, and orofacial somatosensory nuclei (controls, $1.1 \pm 0.1$; NP, $2.3 \pm 0.5 ; p=0.0004$ ), contralateral lateral thalamus encompassing the region of the thalamic reticular nucleus (TRN; controls, $0.9 \pm 0.1 ; \mathrm{NP}, 1.7 \pm 0.3 ; p=0.002)$, and the orofacial representation of contralateral primary somatosensory cortex (S1; controls, $3.2 \pm 0.4$; NP, $7.0 \pm 1.2 ; p=0.0001$; Fig. $2 c$; Table 2, Amplitudes of low-frequency oscillations and fractional amplitudes of low-frequency oscillations). The location of the contralateral somatosensory thalamus was defined by overlaying the change in low-frequency power with functional activation during repeated innocuous brushing of the right side of the mouth as reported previously (Henderson et al., 2013). The location of all other clusters were derived from our previous investigations and human brain atlases (Duvernoy, 1995; Paxinos and Huang, 1995; Mai et al., 2007), and we are confident that the changes reported encompass the nuclei described. We confirmed that these infraslow oscillations were restricted to the frequency range of $0.03-$ $0.06 \mathrm{~Hz}$ by extracting and plotting the entire frequency range $(0-0.25 \mathrm{~Hz}$; Fig. $2 c)$, and we are confident that movement did not have a significant effect on these results because there was no significant difference in movement-related power between controls and NP subjects in any of the six directions $(x, p=0.13 ; y$, $p=0.30 ; z, 0.35$; pitch, $p=0.57$; roll, $p=0.43$; yaw, $p=0.59$ ).

In NP subjects, we found no significant relationship between mean $0.03-0.06 \mathrm{~Hz}$ power in any of these ascending pain pathway clusters identified above with either BDI (ipsilateral SpV, $r=$ $0.35, p=0.19$; contralateral medial thalamus, $r=0.06, p=0.82$; contralateral TRN, $r=-0.06, p=0.82$; contralateral S1, $r=$ $0.11, p=0.67$ ) or PCS (ipsilateral SpV, $r=0.33, p=0.21$; contralateral medial thalamus, $r=-0.03, p=0.92$; contralateral TRN, $r=-0.09, p=0.72$; contralateral S1, $r=0.32, p=0.23$ ). There were also no significant differences in mean power in these clusters in NP subjects on medications compared with those not on medications (mean \pm SEM power; ipsilateral SpV: medications, $10.2 \pm 6.2$; no medications, $8.8 \pm 4.0, p=0.43$; contralateral medial thalamus: medications, $2.4 \pm 0.7$; no medications, $2.2 \pm 0.8, p=0.41$; contralateral TRN: medications, $1.8 \pm 0.5$; no medications, $1.5 \pm 0.4, p=0.329$; contralateral S1: medications, $7.1 \pm 2.1$; no medications, $6.9 \pm 1.3, p=0.46)$. There were also no significant correlations between pain intensity or pain duration and mean $0.03-0.06 \mathrm{~Hz}$ power in any of these ascending pain pathway clusters (pain intensity: ipsilateral SpV, $r=0.05, p=$ 0.86 ; contralateral medial thalamus, $r=-0.18, p=0.51$; contralateral TRN, $r=-0.09, p=0.74$; contralateral S1, $r=-0.09$, $p=0.74$; pain duration: ipsilateral SpV, $r=-0.07, p=0.81$; contralateral medial thalamus, $r=-0.41, p=0.11$; contralateral TRN, $r=-0.50, p=0.06$; contralateral S1, $r=-0.45, p=0.08$ ). Furthermore, reflecting these clusters across the midline revealed no significant differences in mean power between controls and $\mathrm{NP}$ subjects in the ipsilateral SpV (mean \pm SEM power; controls, $8.1 \pm 4.7$; NP subjects, $8.9 \pm 3.7, p=0.45)$, contralateral TRN (controls, $0.9 \pm 0.1$; NP subjects, $1.6 \pm 0.5, p=0.08$ ), or contralateral S1 (controls, $4.2 \pm 0.6$; NP subjects, $4.3 \pm 1.1, p=$ 0.47 ), although there was a significant increase in NP subjects in the contralateral medial thalamus (controls, $0.9 \pm 0.1$; NP subjects, $2.4 \pm 0.5, p=0.003$ ).

To determine whether infra-slow oscillation power increases in the ascending pain pathway were temporally coupled, we performed 

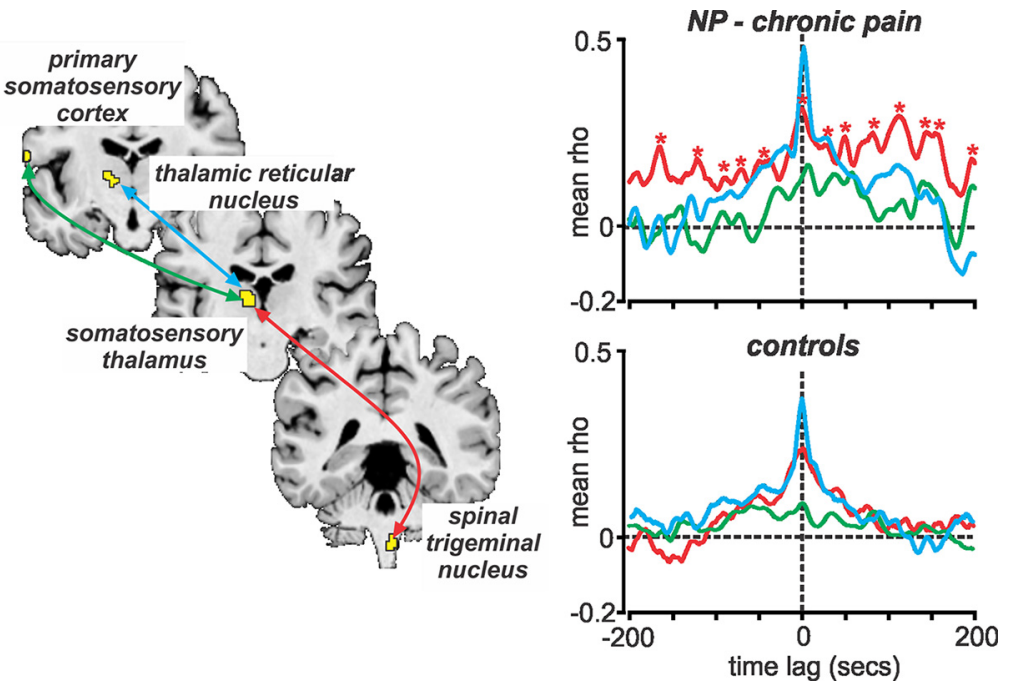

Figure 3. Signal intensity fluctuations in the ascending pain pathway are coupled temporally. Graph shows cross-correlations of resting signal intensity changes within the ascending pain pathway in controls and NP subjects. Tight temporal coupling with zero time lag occurred between the spinal trigeminal nucleus, somatosensory thalamus, and TRN. A lag of $\sim 4$ s occurred between the somatosensory thalamus and cortex. Also note the, in only NP subjects, correlation peaks (indicated by red asterisks) occurred at $\sim 30 \mathrm{~s}$ apart, i.e., indicating ongoing increased infra-slow oscillations in the $0.03 \mathrm{~Hz}$ range.

\section{a Degree centrality}

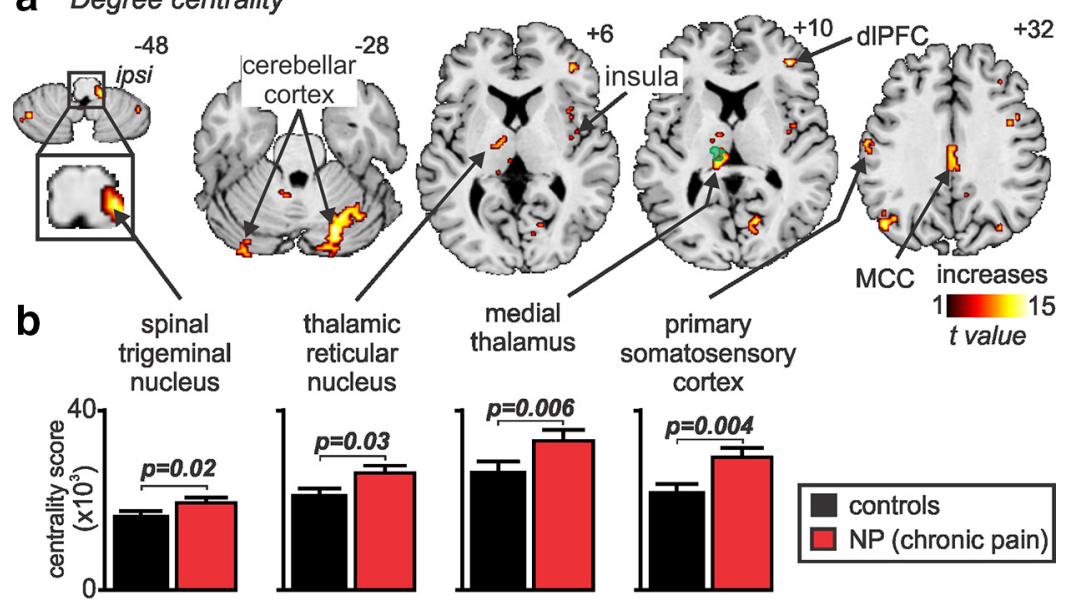

\section{Regional Homogeneity}

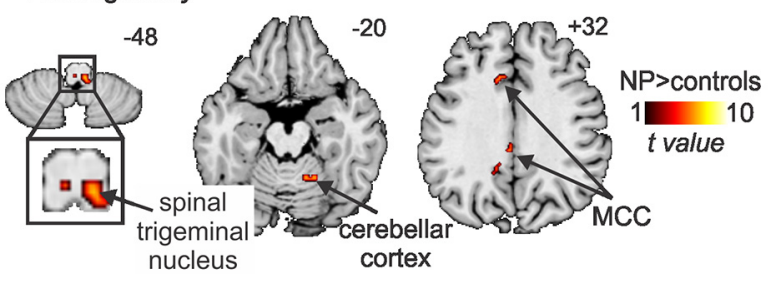

Figure 4. NP is associated with increased degree centrality in the ascending pain pathway and increased regional homogeneity at the primary afferent synapse. $\boldsymbol{a}$, Brain regions in which NP subjects displayed the highest (hot color) degree centrality $(p<0.05$, false discovery rate corrected, minimum cluster size of 10 voxels). Increased degree centrality implies a greater influence of the pain pathway in the overall flow of information through the brain. The location of each axial slice in MNI space is indicated at the top right (z-direction in millimeters). The green shading indicates the thalamic region activated during innocuous brushing of the right lip, i.e., the orofacial somatosensory thalamus. $\boldsymbol{b}$, Plots of mean \pm SEM degree centrality in controls (black) and NP subjects (red) in four regions of the ascending pain pathway. These plots show there is a significant increase in degree centrality in the ascending pain pathway in NP subjects compared with controls. c, NP subjects also displayed greater regional homogeneity than controls, although this increase was restricted to the region of the ipsilateral spinal trigeminal nucleus, cerebellar cortex, and mid-cingulate cortex ( $p<0.05$, false discovery rate corrected, minimum cluster size of 10 voxels). Regional homogeneity evaluates the similarity of the time series within each voxel and its nearest neighbors and could result from local astrocyte activation. AIPFC, Dorsolateral prefrontal cortex; ipsi, ipsilateral; MCC, mid-cingulate cortex. cross-correlation analyses of resting fMRI signal intensity changes between the $\mathrm{SpV}$, medial thalamus, TRN, and S1. In both control and NP subjects, signal intensity coupling occurred between the SpV and medial thalamus and between the medial thalamus and TRN (Fig. 3). However, in NP subjects only, additional correlation peaks occurred at regular time lag intervals of $\sim 30 \mathrm{~s}(0.03$ $\mathrm{Hz}$ ), reflecting the presence of temporally coupled increased infra-slow oscillations within the ascending pain pathway.

\section{Altered network connectivity in ascending pain pathways}

The influence of these low-frequency oscillatory differences within the ascending pain pathway on local network connectivity was assessed by using degree centrality. Network theory methodologies such as degree centrality treat the brain as an integrated network with each voxel considered a node in a network with connections between nodes defined by their resting activity (Bullmore and Sporns, 2009). Degree centrality identifies the most connected nodes by counting the number of other voxels that display similar signal intensity fluctuations. It defines central nodes with the highest number of connections and assumes that the importance of a particular node is dictated by the number of other nodes with which it directly interacts (Joyce et al., 2010). In a remarkably similar pattern to the infra-slow oscillation changes, we found that, in NP subjects, the ascending pain pathway displayed the greatest degree centrality (Fig. $4 a)$. The number of direct connections was significantly greater in NP subjects in the ipsilateral SpV (mean $\pm \mathrm{SEM} \times 10^{3}$ centrality score: controls, $18.7 \pm 1.1$; NP subjects, $22.2 \pm 1.7, p=0.02)$, contralateral medial thalamus (controls, $28.0 \pm$ 2.1; NP subjects, $33.6 \pm 2.3, p=0.006$ ), contralateral TRN (controls, $22.2 \pm 1.6$; NP subjects, $27.3 \pm 1.4, p=0.03$ ), and the orofacial representation of the contralateral S1 (controls, $22.8 \pm 1.4$; NP subjects, $29.7 \pm 2.0, p=0.004$; Fig. $4 b$; Table 2 , Degree centrality). In addition, we found high degree centrality in the cerebellar cortex, contralateral dorsolateral pons, bilateral dorsolateral prefrontal cortex, and the mid-cingulate cortex.

\section{Altered local homogeneity at the primary afferent synapse}

If increased infra-slow oscillation power in NP subjects and the concurrent increase in local network connectivity are associated with increased synchronicity of astrocyte activation and the subsequent 


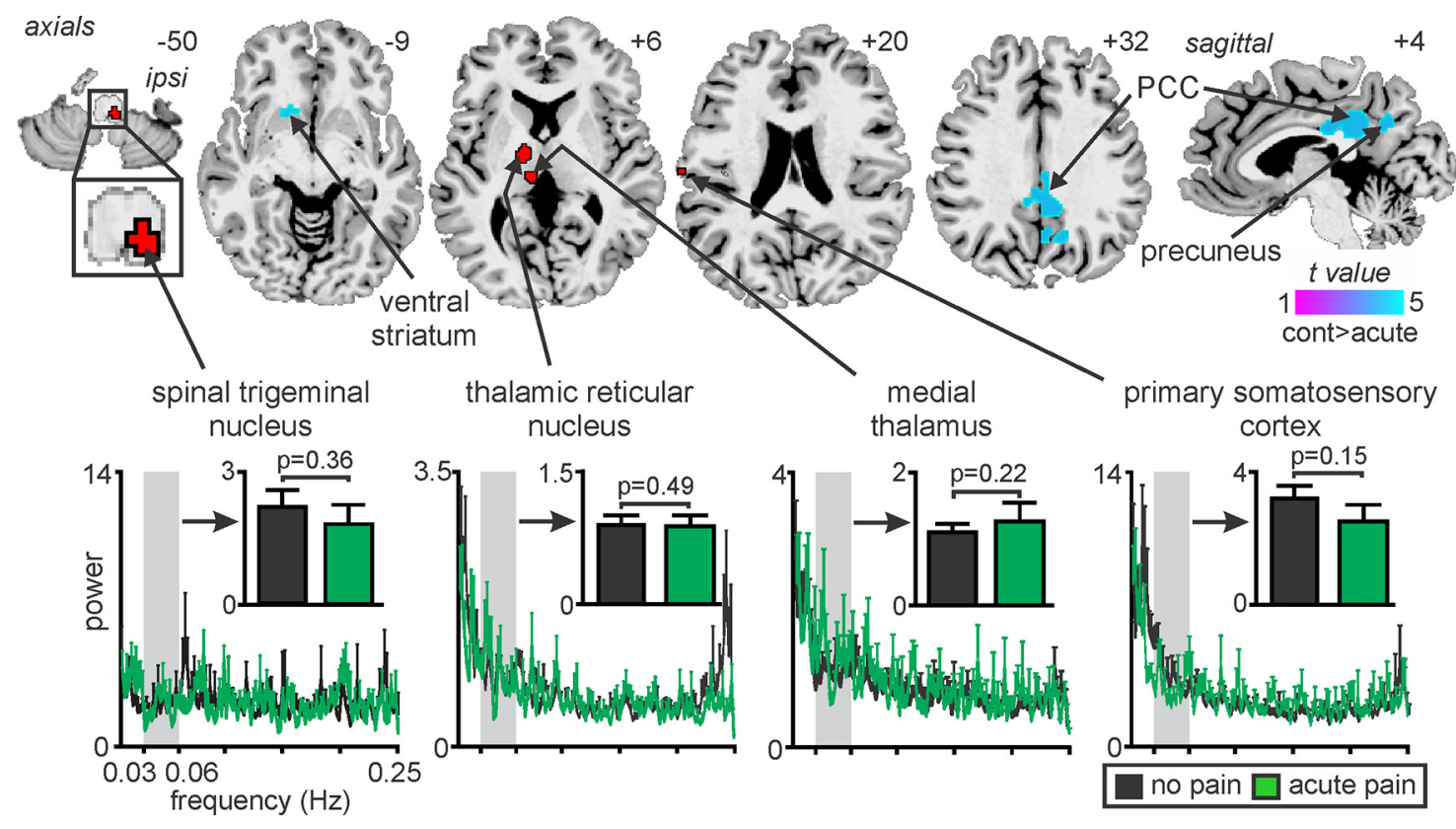

Figure 5. Significant changes in infra-slow oscillation power during acute pain compared with pain-free condition in controls. Acute pain did not evoke increased infra-slow oscillation power in any brain region, but did evoke decreased power (cool color scale) in the contralateral ventral striatum, bilateral posterior cingulate cortex (PCC) and precuneus. Power spectrum plots of four clusters within the ascending pain pathway derived from the analysis between controls and NP subjects are shown in the lower panel. The four clusters chosen were those which in NP subjects displayed increased infra-slow oscillations (red shading). The power spectrum plots as well as plots of mean ( \pm SEM) power between $0.03-0.06 \mathrm{~Hz}$ in controls during acute pain (black) and in controls during no pain (green) show that power was not significantly increased in the ascending pain pathway during acute pain (two-tailed, two-sample $t$ test, $p<0.05$ ). Location of each axial slice in MNI space is indicated at the top right. cont, Controls; ipsi, ipsilateral.

recruitment of surrounding astrocytes and neurons, neighboring voxels should display increased signal intensity synchronization. To determine whether there was such an increase in regional homogeneity, we measured KCC as an index to evaluate the similarity of the time series within each voxel and its 19 nearest neighbors. Remarkably, this analysis revealed that, within the ascending pain pathway, regional homogeneity was increased significantly in NP subjects compared with controls within the ipsilateral SpV (Fig. 4c; Table 2, Regional homogeneity). In addition, increased local homogeneity occurred in the ipsilateral cerebellar cortex and the contralateral mid-cingulate cortex.

\section{No increase in infra-slow oscillations during acute pain}

In a final series of experiments, we aimed to provide additional evidence that the infra-slow oscillation power increases that occur in the ascending pain pathway in NP subjects reflected an ongoing central pathological process and not constant peripheral nociceptor activation. We found that acute orofacial pain (mean \pm SEM intensity, $4.8 \pm 0.3$ of 10 ) did not evoke significant increases in infra-slow oscillation power in any brain region using either ALFF or fALFF analysis procedures. However, we did find significant ALFF decreases during acute pain in the region of the ventral striatum, posterior cingulate cortex, and precuneus (Fig. 5). Importantly, in contrast to individuals with chronic NP, acute pain did not evoke any change in infra-slow oscillation power in the ipsilateral SpV (controls, $2.2 \pm 0.4$; acute pain, $1.9 \pm 0.5, p=$ 0.36 ), contralateral medial thalamus (controls, $1.1 \pm 0.1$; acute pain, $1.3 \pm 0.3, p=0.22$ ), contralateral TRN (controls, $0.9 \pm 0.1$; acute pain, $0.9 \pm 0.2, p=0.49$ ), and contralateral S1 (controls, $3.2 \pm 0.4$; acute pain, $2.5 \pm 0.5, p=0.15$ ).

\section{Discussion}

We describe here a series of experimental findings that show that $\mathrm{NP}$ is associated with increased infra-slow oscillatory activity within the ascending pain pathway. These pain pathway changes are also associated with altered whole-brain network connectivity, as well as local homogeneity changes at the primary afferent synapse. Importantly, these oscillatory and network alterations do not occur during acute noxious stimuli in healthy individuals. The oscillatory and network changes that occur in individuals with chronic NP are consistent with pathological processes that involve astrocyte activation, synaptic modulation, and the development of thalamocortical dysrhythmia.

Although individuals with NP display increased sensitivity in ascending pain pathways (Gracely et al., 1992; Petrou et al., 2012), human brain imaging studies report no increase in cerebral blood flow, an index of neural activity, in these same brain regions (Hsieh et al., 1995; Iadarola et al., 1995; Moisset and Bouhassira, 2007; Youssef et al., 2014). This is curious given that direct neuronal recordings in the human somatosensory thalamus revealed increased burst firing (Lenz et al., 1989), and electroencephalogram recordings report altered thalamocortical rhythm in humans with NP (Sarnthein et al., 2006). Furthermore, thalamocortical dysrhythmia is thought to result from aberrant activity in recurrent thalamocortical loops that involve collaterals to GABAergic neurons in the TRN (Pinault, 2004), and we showed recently reduced TRN blood flow and reduced thalamic GABAergic content in individuals with NP (Henderson et al., 2013; Gustin et al., 2014). Our results show that, in individuals with NP, the pattern of neural activity is indeed altered at multiple levels of the ascending pain pathway.

Infra-slow oscillatory activity is a fundamental property of cerebral and thalamic function and is maintained by adenosine receptor-mediated signaling (Lorincz et al., 2009; Hughes et al., 2011). Adenosine is likely released by astrocytes because they can display spontaneous intracellular infra-slow calcium oscillations (Parri and Crunelli, 2001), are responsive to glutamate and ace- 


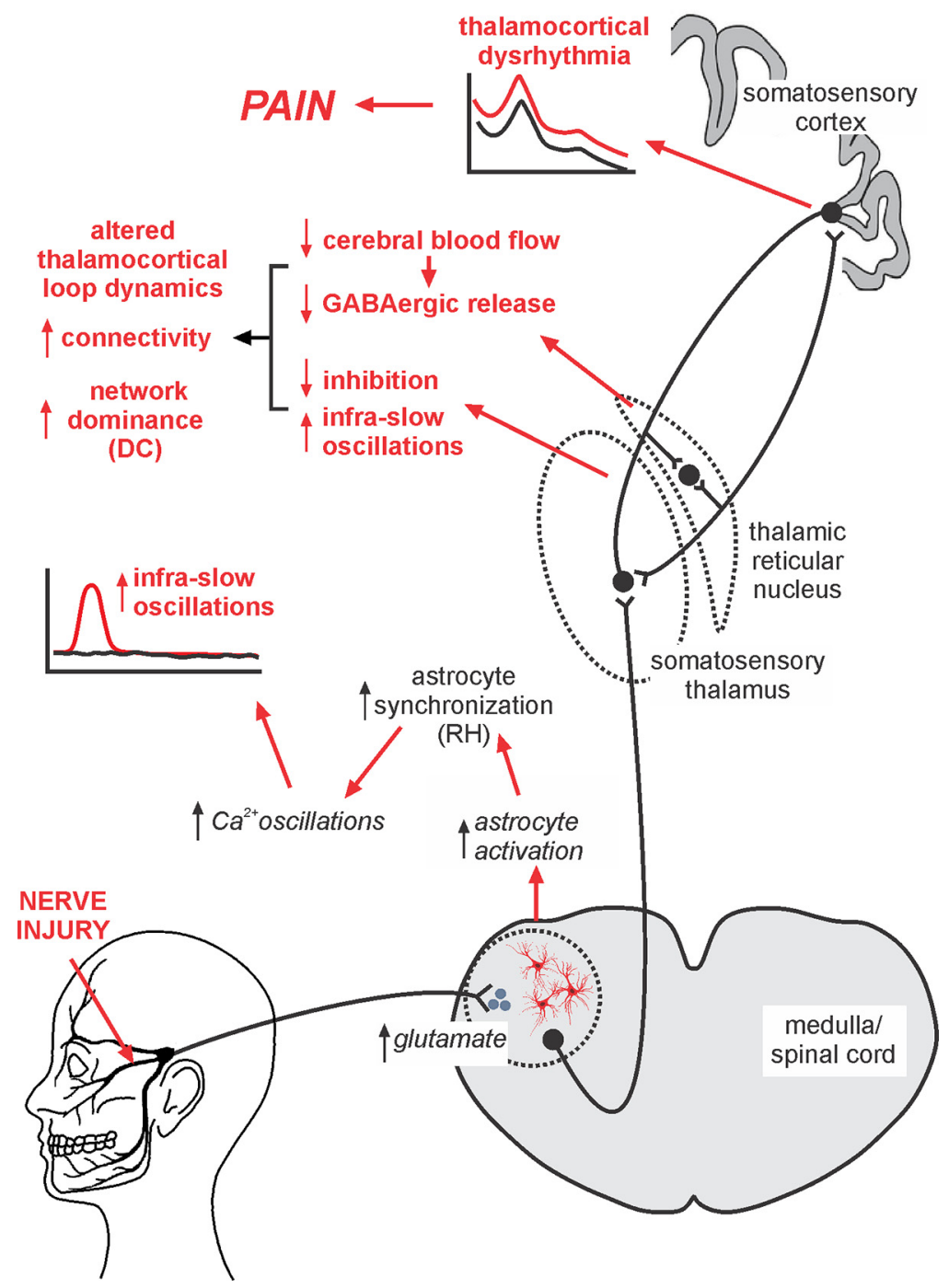

Figure 6. Proposed series of events that result in the maintenance of chronic NP. After nerve injury, excess activity within primary afferent neurons results in excessive neurotransmitter release at the primary afferent synapse. This release results in neural death and elicits astrocyte activation, which results in more regular and increased magnitude calcium waves resulting in increased regional homogeneity $(\mathrm{RH})$. This in turn results in oscillatory gliotransmitter release and increased infra-slow neural oscillations, which are subsequently transferred to the somatosensory thalamus. Additional neural loss in the somatosensory thalamus results in reduced blood flow in the TRN and a subsequent reduction in GABAergic release back onto the somatosensory thalamus. This reduced inhibition combined with increased infra-slow oscillations and the recurrent nature of thalamocortical circuits results in altered thalamocortical connectivity, increased dominance of the ascending pain pathway in overall brain function represented by increased degree centrality (DC), altered thalamocortical loop dynamics, a self-sustaining thalamocortical dysrhythmia, and the constant perception of pain.

tylcholine, and a link between adenosine and infra-slow oscillatory activity has been demonstrated in the cortex (Cunningham et al., 2006). Coincidently, thalamic astrocytes display calcium wave oscillations at approximately the same infra-slow frequency range as the signal oscillations in our NP subjects (Crunelli et al., 2002), and these infra-slow astrocyte calcium waves can propagate among surrounding astrocytes and can elicit large and longlasting NMDA-mediated currents in thalamocortical neurons (Crunelli et al., 2002). Indeed, synchronous burst firing has been linked to astrocyte calcium signaling and associated glutamate release (Tian et al., 2005), and, in pathological situations, greater numbers of astrocytes may display enhanced calcium wave synchrony and amplitude and enhanced NMDA receptor function (Parri and Crunelli, 2001; Halassa et al., 2007). Increased infraslow oscillations are associated with the development of $\alpha$ rhythms into paroxysmal events (Hughes et al., 2011) and are coupled to highfrequency power fluctuations in the cortex (Vanhatalo et al., 2004; Mantini et al., 2007). These data are consistent with the idea that altered astrocyte function in individuals with NP results in increased thalamic infra-slow oscillation power, which in turn evokes increased high-frequency power and the perception of pain (Sarnthein et al., 2006). Although there are well documented microglial changes within ascending pain pathways in humans with NP (Banati, 2002; Loggia et al., 2015), there is no evidence to suggest that they play a role producing the infraslow oscillations.

Although infra-slow oscillations in individuals with NP might be generated independently at multiple sites, evidence suggests that they originate in the primary afferent synapse: (1) there is tight temporal coupling of infra-slow oscillations between regions of the ascending pain pathway; (2) in experimental animal models and human postmortem tissue, NP is associated with astrocyte activation in the dorsal horn/spinal trigeminal nucleus (Garrison et al., 1991; Okada-Ogawa et al., 2009; Shi et al., 2012); (3) trigeminal neuropathy is associated with decreased ipsilateral $\mathrm{SpV}$ mean diffusivity, which is consistent with increased size of activated astrocytes (Wilcox et al., 2015); (4) inhibiting astrocyte activation attenuates and even reverses nerve injuryinduced mechanical allodynia (Zhuang et al., 2006; Churi et al., 2008; Ji et al., 2009, 2013; Morgenweck et al., 2013); (5) despite no current evidence of a direct relationship between regional homogeneity and astrocytic activation, we speculate that increased regional homogeneity in $\mathrm{SpV}$ is consistent with infra-slow frequency calcium waves propagation among neighboring astrocytes; and (6) in an experimental animal model of NP, infra-slow oscillatory activity in somatosensory thalamus was eliminated by severing the connection between the primary afferent synapse and the thalamus (Iwata et al., 2011).

A critical role for astrocyte activation in NP maintenance is consistent with the finding that NP medications, such as valproate, phenytoin, and gabapentin, reduce astrocyte calcium signaling (Tian et al., 2005). Furthermore, inhibition of neural activity or astrocyte activation reverses the mechanical allodyniainduced nerve injury in experimental animals (Wang et al., 2009b). Although some of our NP subjects were taking anticonvulsant medications, they showed similar elevations in infra-slow oscillations as those not taking medications. We cannot determine whether these levels were reduced compared with before medication use and may indeed underlie the fact that we did not find significant relationships between pain intensity and duration 
and infra-slow oscillatory changes in NP subjects. In addition to central changes, it has also been reported that ectopic peripheral afferent discharges contribute to the maintenance of NP (Devor and Seltzer, 1999; Liu et al., 2000). Although these investigations report increased oscillatory firing well above infra-slow levels $(>40 \mathrm{~Hz})$, oscillatory input may maintain glial activation and infra-slow oscillatory activity.

We propose that, after nerve injury, increased activity within primary afferent neurons results in excessive neurotransmitter release, likely glutamatergic. This results in neural death, which likely involves local interneurons because of the following: (1) in animal models of NP, GABAergic interneuron loss occurs in the dorsal horn, which is closely related to glutamate receptor activation (de Novellis et al., 2004; Scholz et al., 2005); and (2) orofacial $\mathrm{NP}$ is associated with reduced gray matter volume and mean diffusivity within SpV (Wilcox et al., 2015). Excess neural discharge also elicits astrocyte activation, spreading oscillating calcium waves, oscillatory gliotransmitter release characterized by increased regional homogeneity, and increased infra-slow neural oscillations throughout the ascending pain pathway. Additionally, local interneuron loss within the somatosensory thalamus resulting from a similar mechanism to that which occurs in SpV results in reduced TRN activity, reduced GABAergic output onto the somatosensory thalamus (Henderson et al., 2013) and, in combination with increased infra-slow oscillatory activity, results in altered thalamocortical connectivity, increased dominance of the ascending pain pathway characterized by increased degree centrality, a self-sustaining thalamocortical dysrhythmia, and the constant perception of pain (Fig. 6).

Although this model points to a critical role for the primary afferent synapse in maintaining NP but does not exclude the possibility that, in different individuals and in different NP conditions, other sites along the ascending pain pathway play a role in pain maintenance. Furthermore, it is possible that increased infra-slow oscillations in regions other than the $\mathrm{SpV}$, thalamus, and $\mathrm{S} 1$ are involved in the maintenance of NP. For example, we found altered infra-slow oscillatory power, degree centrality, and/or regional homogeneity in the cerebellar, dorsolateral prefrontal, mid-cingulate, and insular cortices in NP subjects. In animal models of NP, astrocyte activation occurs in the cingulate cortex, and a recent study suggests that this activation may be related to sleep disturbances (Kuzumaki et al., 2007; Yamashita et al., 2014). Furthermore, increased gene expression indicative of astrocyte activation occurs in the prefrontal cortex of mice with NP that is likely related to pain comorbidities, such as mood disorders (Alvarado et al., 2013). Although the focus of this investigation was on the ascending somatosensory pathway, it is likely that changes in other brain regions, such as association cortices, are involved in maintaining the emotional and cognitive aspects of NP. It is also possible that the changes in infra-slow oscillatory power reported here do not result from astrocyteneural interactions and may result simply from purely neural processes, although we suggest this is less likely.

Finally, there are a number of limitations that need to be recognized. First, given the relatively low spatial resolution of fMRI, it is difficult to accurately localize each cluster to a particular brain nucleus or region. Although we are confident that the cluster locations described in this study include the regions labeled, they also spread into other nuclei. Second, there is a potential bias of circularity introduced by first performing an analysis to determine the frequency band within the thalamus and then using this band to perform voxel-by-voxel analyses (Kriegeskorte et al., 2009; Vul et al., 2009). Unfortunately, we were not able to reduce this circularity bias by performing the analysis on separate groups of subjects because the recruitment of patients with postendodontic chronic pain is challenging and a split analysis would have significantly reduced subject numbers in each group and thus our statistical power. Furthermore, ALFF and fALFF measurements are not independent because they are derived from the same data, although it is recommended that both values are presented because they provide slightly different measures (Zuo et al., 2010). Third, because we were interested in determining changes within the ascending pain pathway, it was necessary to reflect the images of some NP subjects across the midline. Our result suggest that increased infra-slow oscillation patterns are consistent with the contralateral projection of these pain pathways because we did not find a significant difference in power when clusters were reflected across the midline, although there remains a potential issue of lateralized function. Despite these limitations, the discrete changes in infra-slow oscillations in primarily pain-related brain regions make us confident that the changes reported in this investigation are important in the maintenance of NP.

\section{References}

Alvarado S, Tajerian M, Millecamps M, Suderman M, Stone LS, Szyf M (2013) Peripheral nerve injury is accompanied by chronic transcriptome-wide changes in the mouse prefrontal cortex. Mol Pain 9:21. CrossRef Medline

Banati RB (2002) Brain plasticity and microglia: is transsynaptic glial activation in the thalamus after limb denervation linked to cortical plasticity and central sensitisation? J Physiol Paris 96:289-299. CrossRef Medline

Beck AT, Ward CH, Mendelson M, Mock J, Erbaugh J (1961) An inventory for measuring depression. Arch Gen Psychiatry 4:561-571. CrossRef Medline

Bullmore E, Sporns O (2009) Complex brain networks: graph theoretical analysis of structural and functional systems. Nat Rev Neurosci 10: 186-198. CrossRef Medline

Chao-Gan Y, Yu-Feng Z (2010) DPARSF: a MATLAB toolbox for "pipeline" data analysis of resting-state fMRI. Front Syst Neurosci 4:13. CrossRef Medline

Churi SB, Abdel-Aleem OS, Tumber KK, Scuderi-Porter H, Taylor BK (2008) Intrathecal rosiglitazone acts at peroxisome proliferatoractivated receptor-gamma to rapidly inhibit neuropathic pain in rats. J Pain 9:639-649. CrossRef Medline

Crunelli V, Blethyn KL, Cope DW, Hughes SW, Parri HR, Turner JP, Tòth TI Williams SR (2002) Novel neuronal and astrocytic mechanisms in thalamocortical loop dynamics. Philos Trans R Soc Lond B Biol Sci 357: 1675-1693. CrossRef Medline

Cunningham MO, Pervouchine DD, Racca C, Kopell NJ, Davies CH, Jones RS, Traub RD, Whittington MA (2006) Neuronal metabolism governs cortical network response state. Proc Natl Acad Sci U S A 103:5597-5601. CrossRef Medline

de Novellis V, Siniscalco D, Galderisi U, Fuccio C, Nolano M, Santoro L, Cascino A, Roth KA, Rossi F, Maione S (2004) Blockade of glutamate mGlu5 receptors in a rat model of neuropathic pain prevents early overexpression of pro-apoptotic genes and morphological changes in dorsal horn lamina II. Neuropharmacology 46:468-479. CrossRef Medline

Devor M, Seltzer Z (1999) Pathophysiology of damaged nerves in relation to chronic pain. In: Textbook of pain, Ed 4 (Wall PD, Melzack R, eds), pp 129-164. London: Churchill Livingston.

Duvernoy H (1995) The human brainstem and cerebellum. New York: Springer-Verlag Wien.

Farrell MJ, Laird AR, Egan GF (2005) Brain activity associated with painfully hot stimuli applied to the upper limb: a meta-analysis. Hum Brain Mapp 25:129-139. CrossRef Medline

Friston KJ, Holmes AP, Worsley KP, Proline JB, Frith CD, Frackowiak RSJ (1995) Statistical parametric maps in functional imaging: a general imaging approach. Hum Brain Mapp 2:189-210.

Garrison CJ, Dougherty PM, Kajander KC, Carlton SM (1991) Staining of glial fibrillary acidic protein (GFAP) in lumbar spinal cord increases following a sciatic nerve constriction injury. Brain Res 565:1-7. CrossRef Medline 
Gerke MB, Duggan AW, Xu L, Siddall PJ (2003) Thalamic neuronal activity in rats with mechanical allodynia following contusive spinal cord injury. Neuroscience 117:715-722. CrossRef Medline

Giesecke T, Gracely RH, Grant MA, Nachemson A, Petzke F, Williams DA, Clauw DJ (2004) Evidence of augmented central pain processing in idiopathic chronic low back pain. Arthritis Rheum 50:613-623. CrossRef Medline

Gracely RH, Lynch SA, Bennett GJ (1992) Painful neuropathy: altered central processing maintained dynamically by peripheral input. Pain 51: 175-194. CrossRef Medline

Gracely RH, Petzke F, Wolf JM, Clauw DJ (2002) Functional magnetic resonance imaging evidence of augmented pain processing in fibromyalgia. Arthritis Rheum 46:1333-1343. CrossRef Medline

Gustin SM, Peck CC, Wilcox SL, Nash PG, Murray GM, Henderson LA (2011) Different pain, different brain: thalamic anatomy in neuropathic and non-neuropathic chronic pain syndromes. J Neurosci 31:5956-5964. CrossRef Medline

Gustin SM, Wrigley PJ, Youssef AM, McIndoe L, Wilcox SL, Rae CD, Edden RA, Siddall PJ, Henderson LA (2014) Thalamic activity and biochemical changes in individuals with neuropathic pain after spinal cord injury. Pain 155:1027-1036. CrossRef Medline

Halassa MM, Fellin T, Haydon PG (2007) The tripartite synapse: roles for gliotransmission in health and disease. Trends Mol Med 13:54-63. CrossRef Medline

Henderson LA, Peck CC, Petersen ET, Rae CD, Youssef AM, Reeves JM, Wilcox SL, Akhter R, Murray GM, Gustin SM (2013) Chronic pain: lost inhibition? J Neurosci 33:7574-7582. CrossRef Medline

Hsieh JC, Belfrage M, Stone-Elander S, Hansson P, Ingvar M (1995) Central representation of chronic ongoing neuropathic pain studied by positron emission tomography. Pain 63:225-236. CrossRef Medline

Hughes SW, Lorincz ML, Parri HR, Crunelli V (2011) Infraslow $(<0.1 \mathrm{~Hz})$ oscillations in thalamic relay nuclei basic mechanisms and significance to health and disease states. Prog Brain Res 193:145-162. CrossRef Medline

Iadarola MJ, Max MB, Berman KF, Byas-Smith MG, Coghill RC, Gracely RH, Bennett GJ (1995) Unilateral decrease in thalamic activity observed with positron emission tomography in patients with chronic neuropathic pain. Pain 63:55-64. CrossRef Medline

Iwata M, LeBlanc BW, Kadasi LM, Zerah ML, Cosgrove RG, Saab CY (2011) High-frequency stimulation in the ventral posterolateral thalamus reverses electrophysiologic changes and hyperalgesia in a rat model of peripheral neuropathic pain. Pain 152:2505-2513. CrossRef Medline

Ji RR, Gereau RW 4th, Malcangio M, Strichartz GR (2009) MAP kinase and pain. Brain Res Rev 60:135-148. CrossRef Medline

Ji XT, Qian NS, Zhang T, Li JM, Li XK, Wang P, Zhao DS, Huang G, Zhang L, Fei Z, Jia D, Niu L (2013) Spinal astrocytic activation contributes to mechanical allodynia in a rat chemotherapy-induced neuropathic pain model. PLoS One 8:e60733. CrossRef Medline

Joyce KE, Laurienti PJ, Burdette JH, Hayasaka S (2010) A new measure of centrality for brain networks. PLoS One 5:e12200. CrossRef Medline

Kriegeskorte N, Simmons WK, Bellgowan PS, Baker CI (2009) Circular analysis in systems neuroscience: the dangers of double dipping. Nat Neurosci 12:535-540. CrossRef Medline

Kuzumaki N, Narita M, Hareyama N, Niikura K, Nagumo Y, Nozaki H, Amano T, Suzuki T (2007) Chronic pain-induced astrocyte activation in the cingulate cortex with no change in neural or glial differentiation from neural stem cells in mice. Neurosci Lett 415:22-27. CrossRef Medline

Lenz FA, Kwan HC, Dostrovsky JO, Tasker RR (1989) Characteristics of the bursting pattern of action potentials that occurs in the thalamus of patients with central pain. Brain Res 496:357-360. CrossRef Medline

Liu CN, Michaelis M, Amir R, Devor M (2000) Spinal nerve injury enhances subthreshold membrane potential oscillations in DRG neurons: relation to neuropathic pain. J Neurophysiol 84:205-215. Medline

Loggia ML, Chonde DB, Akeju O, Arabasz G, Catana C, Edwards RR, Hill E, Hsu S, Izquierdo-Garcia D, Ji RR, Riley M, Wasan AD, Zürcher NR, Albrecht DS, Vangel MG, Rosen BR, Napadow V, Hooker JM (2015) Evidence for brain glial activation in chronic pain patients. Brain 138: 604-615. CrossRef Medline

Lörincz ML, Geall F, Bao Y, Crunelli V, Hughes SW (2009) ATP-dependent infra-slow $(<0.1 \mathrm{~Hz})$ oscillations in thalamic networks. PLoS One 4:e4447. CrossRef Medline
Macey PM, Macey KE, Kumar R, Harper RM (2004) A method for removal of global effects from fMRI time series. Neuroimage 22:360-366. CrossRef Medline

Mai JK, Paxinos G, Voss T (2007) Atlas of the human brain, Ed 3. San Diego: Academic.

Mantini D, Perrucci MG, Del Gratta C, Romani GL, Corbetta M (2007) Electrophysiological signatures of resting state networks in the human brain. Proc Natl Acad Sci U S A 104:13170-13175. CrossRef Medline

Moisset X, Bouhassira D (2007) Brain imaging of neuropathic pain. Neuroimage 37 [Suppl 1]:S80-S88. CrossRef Medline

Morgenweck J, Griggs RB, Donahue RR, Zadina JE, Taylor BK (2013) PPARgamma activation blocks development and reduces established neuropathic pain in rats. Neuropharmacology 70:236-246. CrossRef Medline

Nurmikko TJ, Eldridge PR (2001) Trigeminal neuralgia-pathophysiology, diagnosis and current treatment. Br J Anaesth 87:117-132. CrossRef Medline

Okada-Ogawa A, Suzuki I, Sessle BJ, Chiang CY, Salter MW, Dostrovsky JO, Tsuboi Y, Kondo M, Kitagawa J, Kobayashi A, Noma N, Imamura Y, Iwata K (2009) Astroglia in medullary dorsal horn (trigeminal spinal subnucleus caudalis) are involved in trigeminal neuropathic pain mechanisms. J Neurosci 29:11161-11171. CrossRef Medline

Parri HR, Crunelli V (2001) Pacemaker calcium oscillations in thalamic astrocytes in situ. Neuroreport 12:3897-3900. CrossRef Medline

Paxinos G, Huang X (1995) Atlas of the human brainstem, Ed 1. San Diego: Academic.

Petrou M, Pop-Busui R, Foerster BR, Edden RA, Callaghan BC, Harte SE, Harris RE, Clauw DJ, Feldman EL (2012) Altered excitation-inhibition balance in the brain of patients with diabetic neuropathy. Acad Radiol 19:607-612. CrossRef Medline

Pinault D (2004) The thalamic reticular nucleus: structure, function and concept. Brain Res Brain Res Rev 46:1-31. CrossRef Medline

Sarnthein J, Stern J, Aufenberg C, Rousson V, Jeanmonod D (2006) Increased EEG power and slowed dominant frequency in patients with neurogenic pain. Brain 129:55-64. CrossRef Medline

Scholz J, Broom DC, Youn DH, Mills CD, Kohno T, Suter MR, Moore KA, Decosterd I, Coggeshall RE, Woolf CJ (2005) Blocking caspase activity prevents transsynaptic neuronal apoptosis and the loss of inhibition in lamina II of the dorsal horn after peripheral nerve injury. J Neurosci 25:7317-7323. CrossRef Medline

Shi Y, Gelman BB, Lisinicchia JG, Tang SJ (2012) Chronic-pain-associated astrocytic reaction in the spinal cord dorsal horn of human immunodeficiency virus-infected patients. J Neurosci 32:10833-10840. CrossRef Medline

Song XW, Dong ZY, Long XY, Li SF, Zuo XN, Zhu CZ, He Y, Yan CG, Zang YF (2011) REST: a toolkit for resting-state functional magnetic resonance imaging data processing. PLoS One 6:e25031. CrossRef Medline

Sullivan MJL, Bishop S, Pivik J (1995) The pain catastrophizing scale: development and validation. Psychol Assess 7:432-524. CrossRef

Tian GF, Azmi H, Takano T, Xu Q, Peng W, Lin J, Oberheim N, Lou N, Wang X, Zielke HR, Kang J, Nedergaard M (2005) An astrocytic basis of epilepsy. Nat Med 11:973-981. CrossRef Medline

Vanhatalo S, Palva JM, Holmes MD, Miller JW, Voipio J, Kaila K (2004) Infraslow oscillations modulate excitability and interictal epileptic activity in the human cortex during sleep. Proc Natl Acad Sci U S A 101: 5053-5057. CrossRef Medline

Vul E, Harris C, Winkielman P, Pashler H (2009) Puzzlingly high correlations in fMRI studies of emotion, personality, and social cognition. Perspect Psychol Sci 4:274-290. CrossRef Medline

Walton KD, Llinás RR (2010) Central pain as a thalamocortical dysrhythmia: a thalamic efference disconnection? In: Translational pain research: from mouse to man (Kruger L, Light AR, eds). Boca Raton, FL: CRC.

Wang SH, Liang CT, Liu YW, Huang MC, Huang SC, Hong WF, Su JG (2009a) Crosstalk between activated forms of the aryl hydrocarbon receptor and glucocorticoid receptor. Toxicology 262:87-97. CrossRef Medline

Wang W, Mei X, Huang J, Wei Y, Wang Y, Wu S, Li Y (2009b) Crosstalk between spinal astrocytes and neurons in nerve injury-induced neuropathic pain. PLoS One 4:e6973. CrossRef Medline

Wang W, Li Q, Yamada T, Matsumoto K, Matsumoto I, Oda M, Watanabe G, Kayano Y, Nishioka Y, Sone S, Yano S (2009c) Crosstalk to stromal 
fibroblasts induces resistance of lung cancer to epidermal growth factor receptor tyrosine kinase inhibitors. Clin Cancer Res 15:6630-6638. CrossRef Medline

Wilcox SL, Gustin SM, Macey PM, Peck CC, Murray GM, Henderson LA (2015) Anatomical changes at the level of the primary synapse in neuropathic pain: evidence from the spinal trigeminal nucleus. J Neurosci 35: 2508-2515. CrossRef Medline

Yamashita A, Hamada A, Suhara Y, Kawabe R, Yanase M, Kuzumaki N, Narita M, Matsui R, Okano H (2014) Astrocytic activation in the anterior cingulate cortex is critical for sleep disorder under neuropathic pain. Synapse 68:235-247. CrossRef Medline

Youssef AM, Gustin SM, Nash PG, Reeves JM, Petersen ET, Peck CC, Murray
GM, Henderson LA (2014) Differential brain activity in subjects with painful trigeminal neuropathy and painful temporomandibular disorder. Pain 155:467-475. CrossRef Medline

Zhuang ZY, Wen YR, Zhang DR, Borsello T, Bonny C, Strichartz GR, Decosterd I, Ji RR (2006) A peptide c-Jun N-terminal kinase (JNK) inhibitor blocks mechanical allodynia after spinal nerve ligation: respective roles of JNK activation in primary sensory neurons and spinal astrocytes for neuropathic pain development and maintenance. J Neurosci 26: 3551-3560. CrossRef Medline

Zuo XN, Di Martino A, Kelly C, Shehzad ZE, Gee DG, Klein DF, Castellanos FX, Biswal BB, Milham MP (2010) The oscillating brain: complex and reliable. Neuroimage 49:1432-1445. CrossRef Medline 